\title{
Elevated Pre-injection Basal Luteinizing Hormone Concentrations are Common in Girls Treated for Central Precocious Puberty
}

\author{
(D) Stefanie Schubert ${ }^{1}$, (D) Amalie H. Hvelplund ${ }^{1}$, (D) Aase Handberg2 ${ }^{\text {, (D) S } \varnothing r e n ~ H a g s t r o e m ~}{ }^{1}$, (D) Tina Lund Leunbach ${ }^{1,3}$ \\ ${ }^{1}$ Aalborg University Hospital, Clinic of Pediatrics, Aalborg, Denmark \\ ${ }^{2}$ Aalborg University Hospital, Clinic of Clinical Biochemistry; Aalborg University, Department of Clinical Medicine, Aalborg, Denmark \\ ${ }^{3}$ Aarhus University Hospital, Clinic of Paediatrics and Adolescent Medicine, Aarhus, Denmark
}

\begin{abstract}
What is already known on this topic?
Gonadotropin-releasing hormone agonists (GnRHa) reduce gonadotropic activity and are efficient in suppressing pubertal progression in precocious puberty. Pituitary suppression during GnRHa therapy is optimally assessed by GnRH stimulation.
\end{abstract}

\section{What this study adds?}

Pre-injection basal luteinizing hormone (LH) remains at pubertal concentrations in the majority of girls during GnRHa therapy in spite of lack of pubertal progression, a significant decline in bone age and height standard deviation score. Even after shortened intervals with subcutaneous administration of leuproreline $3.75 \mathrm{mg}$ in girls suspected to have progressive pubertal development during treatment of central precocious puberty (CPP), pre-injection basal LH did not drop to prepubertal concentrations in $86 \%$ of patients.

\section{Abstract}

Objective: A consensus on how to monitor girls with central precocious puberty (CPP) during gonadotropin-releasing hormone agonist (GnRHa) treatment is lacking. Increased, unstimulated basal luteinizing hormone (LH) concentrations have been suggested to indicate lack of suppression. The aim was to evaluate pre-injection basal LH concentrations during GnRHa (leuprorelin 3.75 mg) treatment every four weeks in girls with CPP.

Methods: Medical records were reviewed for girls with CPP treated at a single center from 2014-2019. Clinical characteristics and laboratory findings during treatment were systematically recorded.

Results: A total of 587 GnRHa pre-injection basal LH concentrations were analyzed in 74 girls. Basal LH was pubertal ( $\geq 0.3$ IU/L) in $53.5 \%$ of blood samples and $87.8 \%$ of all girls had a pubertal basal LH concentration at least once. A GnRH test ( $n=29)$ was repeated in 23 girls due to suspicion of clinical progression, elevated basal LH or recordable estradiol concentrations. None had a stimulated LH $>3.1 \mathrm{IU} / \mathrm{L}$. The predictability of treatment suppression (specificity) of basal LH concentrations was $12.0 \%$ when compared to repeated GnRH stimulation tests. Despite shortening the GnRHa injection interval to three weeks, basal LH concentrations remained pubertal in $85.7 \%$ girls. A significant reduction in height standard deviation score $(p<0.001)$ and bone age advance $(p<0.001)$ was observed during treatment.

Conclusion: Pre-injection basal LH remains at pubertal concentrations during treatment with leuprorelin 3.75 mg in girls with CPP. Clinical monitoring of pubertal progression is preferable to routine basal LH concentrations. Repeat GnRH stimulation testing should be regarded as the gold standard.

Keywords: Girls, precocious puberty, luteinizing hormone, gonadotropin-releasing hormone agonist, gonadotropin-releasing hormone test

\section{Introduction}

Central precocious puberty (CPP) in girls is often idiopathic, in up to $90 \%$ of affected girls $(1,2)$. Gonadotropin-releasing hormone (GnRH) agonists (GnRHa) are used to suppress pubertal development by stimulating GnRH receptors continuously, causing pituitary desensitization and reduced
Address for Correspondence: Tina Lund Leunbach MD, Aalborg University Hospital, Clinic of Pediatrics; Aarhus University Hospital, Clinic of Paediatrics and Adolescent Medicine, Aarhus, Denmark Phone: +0045 78451474 E-mail: tileun@rm.dk ORCID: orcid.org/0000-0001-7996-7596

${ }^{-}$Copyright 2021 by Turkish Pediatric Endocrinology and Diabetes Society

The Journal of Clinical Research in Pediatric Endocrinology published by Galenos Publishing House.
Conflict of interest: None declared Received: 16.09 .2020 Accepted: 17.12 .2020 
gonadotropic activity $(3,4,5)$. The use of GnRHa has increased in recent years $(6,7)$. However, there is still no consensus on how to monitor the pituitary suppression during GnRHa treatment (8). It has been suggested that increased basal luteinizing hormone (LH) concentrations indicate lack of suppression $(8,9,10)$. In case basal $\mathrm{LH}$ concentrations provide the same information as a $\mathrm{GnRH}$ stimulation test, monitoring would be less time consuming, costly and less invasive for the patients (11).

The aims of this study were to assess if pre-injection basal LH concentrations are reliable as a proxy for clinical progression of puberty during GnRHa treatment, and to test if basal LH concentrations are in accordance with GnRH stimulated LH concentrations under GnRHa suppressive treatment.

\section{Methods}

A review was undertaken of a cohort of girls followed at the Department of Pediatrics, Aalborg University Hospital, Denmark and who were treated with leuprorelin acetate $3.75 \mathrm{mg}$ injections every four weeks for CPP. The electronic patient system (Clinical Suite 2017, DXC technology, Tysons, Virginia, USA) was searched using the International Classification of Diseases-10 codes for CPP (DE228A) and associated diagnosis [early puberty (DE301), hormonal dysregulation in puberty (DE309), premature thelarche (DE308A)]. All girls with the above-mentioned codes, who attended the Department of Pediatrics at Aalborg University Hospital between January 2014 and September 2019, were identified (Figure 1).

Only girls who had a pubertal response (stimulated LH $>5 \mathrm{IU} / \mathrm{L}$ ) at time 30 minutes during a GnRH stimulation test (gonadorelin $0.1 \mathrm{mg}$ intravenous) and who started subcutaneous injections with leuprorelin acetate $3.75 \mathrm{mg}$ at four-weekly intervals were included (Figure 1). Previous medical history was extracted from the medical notes retrospectively from the first contact.

Data were collected systematically from the electronic patient records by two investigators (AH, SS) according to a predefined protocol. A third researcher was consulted in unclear cases (TL). At first visit: age at presentation, Tanner stage (12), presenting symptoms, family pubertal history, height and weight were noted. Dates and results of the diagnostic GnRH stimulation tests and of repeated GnRH stimulation tests were obtained. Dates, GnRHa preinjection basal gonadotropin concentrations and estradiol concentrations were noted. Hormonal blood samples and clinical examinations were undertaken regularly at 3-6 months intervals by pediatricians. A pre-injection basal

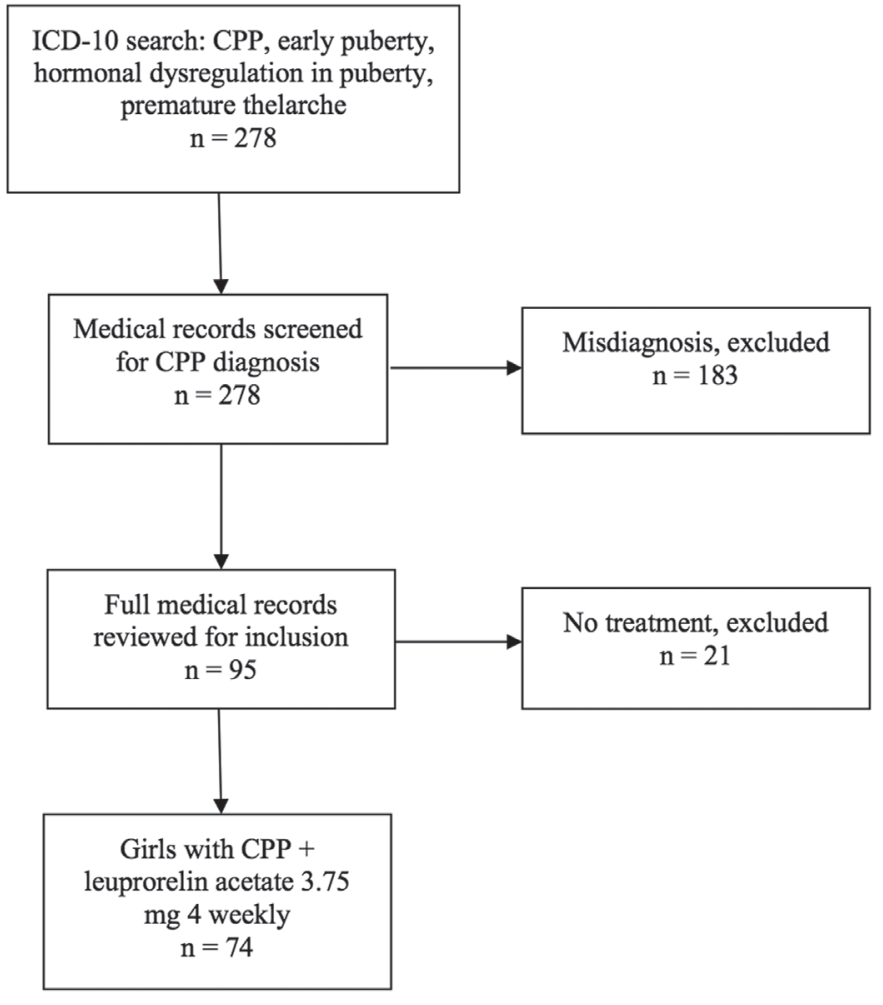

Figure 1. Flowchart showing patient inclusion and exclusion criteria in gonadotropin-releasing hormone agonists treated girls with central precocious puberty

ICD-10: International Classification of Diseases-10, CPP: central precocious puberty

LH $\geq 0.3$ IU/L was considered pubertal. A stimulated LH/ follicle stimulating hormone (FSH) ratio $>1$ was interpreted to indicate breakthrough of hypothalamic suppression. During follow-up, bone age (BA), brain magnetic resonance imaging (MRI) and hormonal blood samples (pre-injection basal gonadotropins, estradiol) were recorded. At the final clinical visit, age, height, weight and treatment status were noted. Standard deviation (SD) scores (SDS) of height and body mass index (BMI) were calculated based on Danish reference data (13).

Heights and weights were measured in clinic by a specialist endocrine nurse using a stadiometer with a precision of 0.1 $\mathrm{cm}$ or $0.1 \mathrm{~kg}$, respectively. BAs were assessed according to Greulich \& Pyle using BoneExpert Software (Visiana Aps, Denmark) on X-ray images of the left hand and wrist. LH, FSH, and estradiol were analyzed on Roche-Cobas $8000^{\circledR}$ immunochemistry module (Roche, Mannheim, Germany) by electro-chemiluminescense immunoassay. Limit of detection was $0.1 \mathrm{IU} / \mathrm{L}$ for $\mathrm{LH}$ and $20 \mathrm{pmol} / \mathrm{L}$ for estradiol. Interserial coefficient of variation at the detection limits were $<20 \%$. Interserial coefficients of variation were $5.2 \%$ 
at $0.5 \mathrm{IU} / \mathrm{L}$ and $2.0 \%$ at $6.2 \mathrm{IU} / \mathrm{L}$ for $\mathrm{LH}$ and $11.0 \%$ at 360 $\mathrm{pmol} / \mathrm{L}$ for estradiol. The laboratory is ISO 15189 accredited.

The study protocol was approved by the hospital management (journal no 2019-005812-58) as required by Danish law.

\section{Statistical Analyses}

Descriptive data were presented as mean \pm SD or median (range) according to normal or non-parametric distribution. A paired t-test for parametric data was used to compare two variables in the same individual. An unpaired t-test was used for comparison of two independent groups. A MannWhitney U test was applied to compare non-parametric data. Pearson correlation coefficient was used to calculate the correlation between two parametric variables. Predictability of treatment suppression by basal LH concentrations was assessed by comparison of prepubertal basal LH concentrations among girls with fully suppressed GnRH responses $(\mathrm{LH}<5 \mathrm{IU} / \mathrm{L}$ and $\mathrm{LH} / \mathrm{FSH}$ ratio $<1$ ) who had a second stimulation test. A $p$ value of $<0.05$ was considered significant.

\section{Results}

\section{Population Characteristics}

Inclusion criteria were fulfilled by 74 girls (Table 1). The mean presenting age in hospital was $8.0 \pm 1.2$ years. Mean age at onset of treatment was $8.2 \pm 1.3$ years. Within the time period the medical course was complete for 55 girls and the average duration of treatment was $2.8 \pm 1.2$ years until age $11.2 \pm 0.7$ years. The remaining 19 girls still had ongoing treatment at completion of the study.

Two girls $(2.7 \%)$ had reached menarche at the first visit and they were clinically described to be at Tanner stage B3 and B4. Special circumstances with mental retardation or cerebral palsy influenced the decision to treat in two cases. Concern about psychosocial stressors related to early puberty contributed to the decision of treatment in 16 girls $(21.6 \%)$. A family history of early puberty was confirmed by 18 families $(24.3 \%)$, and another eight girls $(10.8 \%)$ had an increased risk due to international adoption.

Average height SDS (Table 1) at first visit was above mean for age but proportional to average BMI SDS. At final visit height SDS approached the mean for age whereas age adjusted BMI SDS had increased $(p<0.001)$ (Table 1). BA was examined in all girls at the first clinical visit and the mean BA was $1.2 \pm 1.1$ years ahead of the chronological age (CA). Consecutive BAs were undertaken in 52 girls $(70.3 \%)$ and the BA advance regressed and approached CA over time $(0.5 \pm 1.0$ years) $(p<0.001)$ (Table 1$)$.
Table 1. Clinical and radiological characteristics at first and final clinical visit

\begin{tabular}{|c|c|c|}
\hline & $\begin{array}{l}\text { First visit } \\
\mathrm{n}=74 \\
\text { Mean } \pm \mathrm{SD}\end{array}$ & $\begin{array}{l}\text { Final visit } \\
\mathrm{n}=74 \\
\text { Mean } \pm \mathrm{SD}\end{array}$ \\
\hline Age (years) & $8.0 \pm 1.2$ & $10.7 \pm 1.2$ \\
\hline Age-treatment (years) & $8.2 \pm 1.3$ & $11.2 \pm 0.7^{*}$ \\
\hline BA advancement (years) & $1.2 \pm 1.1$ & $0.5 \pm 1.0 * *$ \\
\hline Height (SDS) & $0.9 \pm 1.6$ & $0.6 \pm 1.6$ \\
\hline BMI (SDS) & $0.7 \pm 1.1$ & $1.2 \pm 1.0$ \\
\hline \multicolumn{3}{|l|}{ Presenting symptoms [n (\%)] } \\
\hline Breast development & $68(91.9 \%)$ & \\
\hline Growth acceleration & $34(46.0 \%)$ & \\
\hline Menarche & $2(2.7 \%)$ & \\
\hline Adrenarche (hair, sweat, acne) & $46(62.2 \%)$ & \\
\hline Mood swings & $18(24.3 \%)$ & \\
\hline
\end{tabular}

Brain MRIs were undertaken in 58 girls $(78.4 \%)$ at a mean age of $7.7 \pm 1.2$ years (range 3.0 to 9.7 ).

The oldest girl had a rapid pubertal development with menarche at age 9.7 years at Tanner stage 3, for which she started GnRHa therapy.

Six girls $(10.3 \%)$ with a mean age of $6.2 \pm 2.3$ years (range 3.0 to 9.3) had abnormal findings, including hamartomas or sequalae from brain trauma (Table 2). One girl, aged 9.3 years, had multiple MRI scans (ID 1, Table 2); the one presented here was closest to the time when leuprorelin was started (due to psychological reasons). Four girls had incidentalomas (Table 2).

\section{Pre-injection Basal LH Concentrations}

During treatment with GnRHa, 587 blood samples (7.9 per girl, range 1 to 20) were analyzed for pre-injection basal LH, FSH and estradiol. Basal LH was $\geq 0.3$ IU/L in 314 samples $(53.5 \%)$ and 65 girls $(87.8 \%)$ had a basal LH $\geq 0.3$ IU/L at some point in time. There was no declining temporal trend of pre-injection basal LH concentrations during treatment $(r=0.09)$ (Figure 2). Basal LH concentrations were $\geq 1.1 \mathrm{IU} / \mathrm{L}$ (range 1.1 to 2.4) in 10 girls at least once during treatment. Three of these girls had a repeat GnRH stimulation test of which one had a LH/FSH ratio $>1$ and consequently the GnRHa dosing interval was reduced to 3 weeks.

\section{Repeat GnRH Stimulation Tests}

A GnRH stimulation test was repeated $(n=29)$ in 23 girls (31.1\%) (six girls had two tests). Four girls (17.4\%) had a ratio of $\mathrm{LH} / \mathrm{FSH}>1$, but none had a stimulated $\mathrm{LH}>3.1$ 
IU/L. Unstimulated basal LH concentrations drawn prior to GnRH injection were $0.2 \mathrm{IU} / \mathrm{L}, 0.4 \mathrm{IU} / \mathrm{L}, 0.7 \mathrm{IU} / \mathrm{L}$ and 1.1 IU/L, respectively.

The remaining $25 \mathrm{GnRH}$ stimulation tests showed LH/ FSH ratios $<1$ and LH peaks $\leq 2.9$ IU/L. Three tests were preceded by pre-pubertal basal LH concentrations $(<0.3$ IU/L) and 22 tests had pubertal basal LH concentrations $\geq 0.3$ IU/L (median $0.4 \mathrm{IU} / \mathrm{L}$, range 0.3 to $2.2 \mathrm{IU} / \mathrm{L}$ ) at least once prior to the test. Thus, the predictability of proper treatment suppression (specificity) according to pre-injection basal LH was $12.0 \%$ (Figure 3).

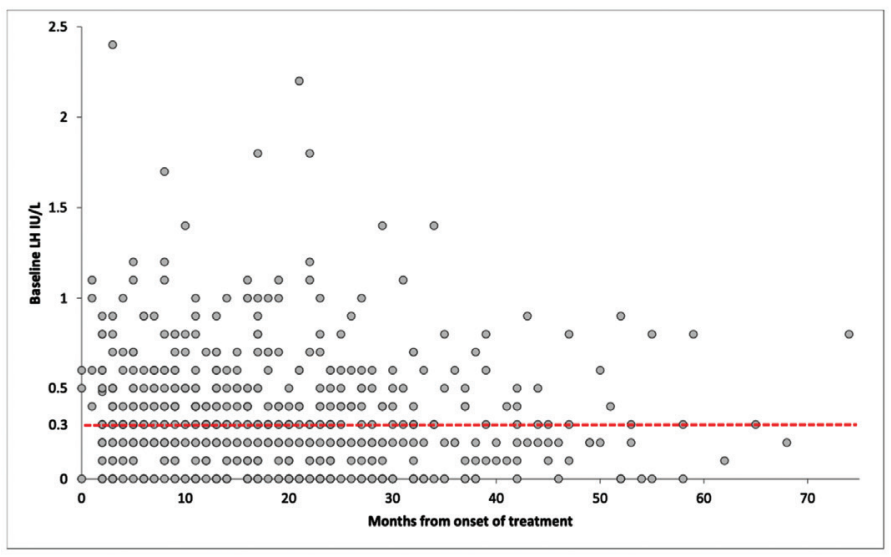

Figure 2. Pre-injection basal luteinizing hormone (LH) concentrations during gonadotropin-releasing hormone agonists (GnRHa) treatment for central precocious puberty. All samples were drawn just prior to the next GnRHa injection. The horizontal dashed line indicates the cut-off for a pubertal baseline $\mathrm{LH}$ concentration

LH: luteinizing hormone
There was no significant difference $(p=0.354)$ in median basal LH concentrations between tests with $\mathrm{LH}>\mathrm{FSH}$ $(17.4 \%)(0.6 \mathrm{IU} / \mathrm{L}$, range $0.2-1.1)$ and suppressed tests $(0.4$ IU/L, range 0.3-2.2).

The mean time from the diagnostic GnRH stimulation test to the first repeated test was $1.7 \pm 0.9$ years (range 0.4 to 3.8). The likelihood of having a pubertal response on repeat GnRH testing was poorly correlated with the time from diagnosis to repeated testing $(r=0.4)$. Likewise, the CA was not associated with an increased risk $(r=0.1)$. When comparing the groups of girls with and without a repeat GnRH stimulation test, there was no significant difference in BMI SDS at first $(p=0.255)$ and last contact $(p=0.248)$.

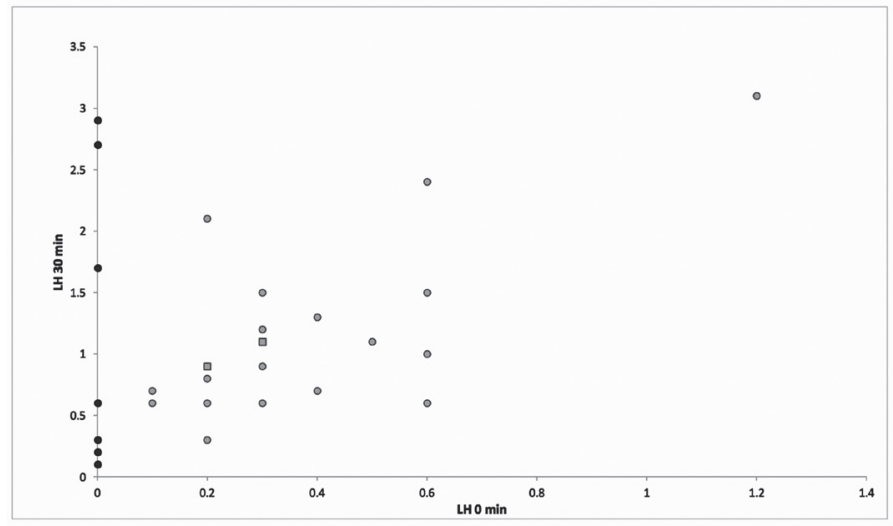

Figure 3. Luteinizing hormone (LH) concentrations (IU/L) at time 0 and 30 minutes at repeat gonadotropin-releasing hormone stimulation retesting. $\mathrm{LH}$ concentrations $<0.1$ are marked as 0 (dark blue circle). Two tests had equal concentrations (square)

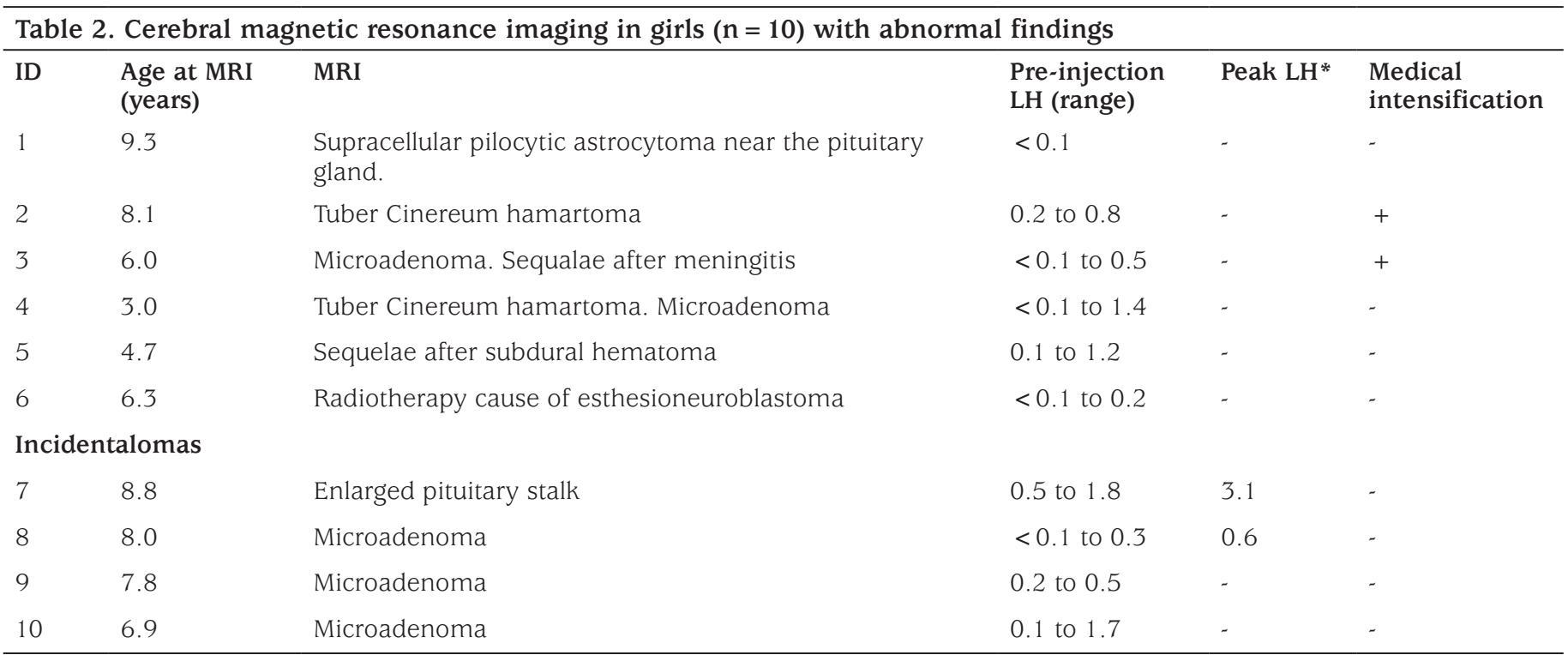

*Girls who had a repeat gonadotropin-releasing hormone stimulation test during therapy. MRI: magnetic resonance imaging, LH: luteinizing hormone 


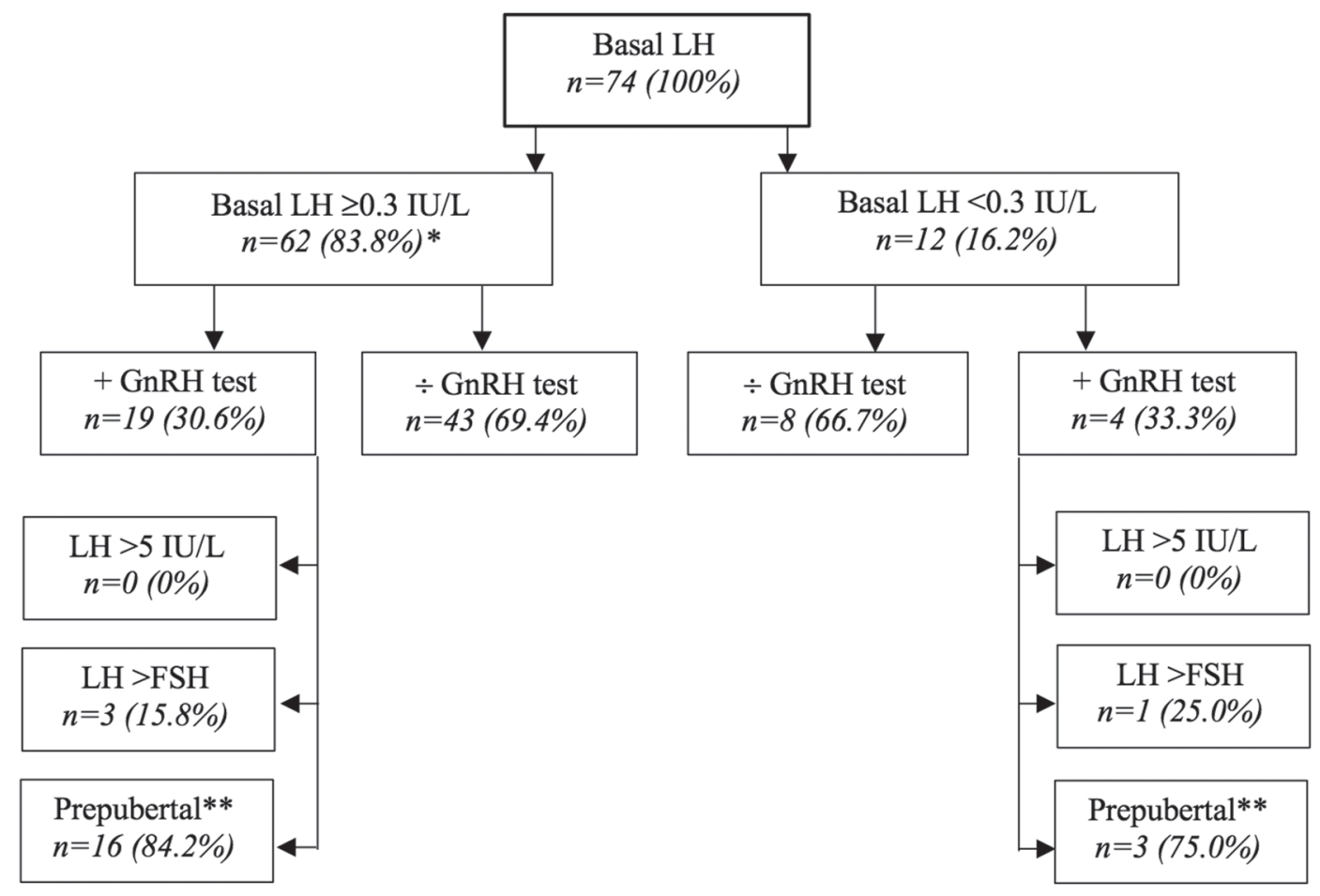

Figure 4. Girls split according to pre-injection basal luteinizing hormone concentrations prior to repeat gonadotropin-releasing hormone agonists $(\mathrm{GnRH})$ testing ( + had repeat GnRH test/ - had no repeat GnRH test). Girls who had a repeat GnRH test $(\mathrm{n}=23$ ) are only represented once. If more than one repeat test was undertaken ( $n=6$ girls) the first test in time was used unless overruled by a pubertal response at the second test $(n=1)$

${ }^{*} N=62$ girls had LH $\geq 0.3 \mathrm{IU} / \mathrm{L}$ minimum once, up until the first repeat GnRH test (another three girls developed LH concentrations $\geq 0.3$ IU/L after the first GnRH test and are not included in the figure).

* * Prepubertal: $L H<5$ IU/L and LH <FSH.

LH: luteinizing hormone, FSH: follicle stimulating hormone

During repeat GnRH testing a poor correlation between basal and stimulated LH concentrations was observed $(r=0.4)$ (Figure 4).

\section{Estradiol}

In 33 of 74 girls $(44.6 \%)$ estradiol was detectable $(\geq 20$ $\mathrm{pmol} / \mathrm{L})$ at some point in time. The estradiol concentrations were significantly higher at diagnosis (median 100 pmol/L, range 30 to 320) than during treatment (median $40 \mathrm{pmol} / \mathrm{L}$, range 20 to 380$)(\mathrm{p}<0.001)$. Estradiol was $>100 \mathrm{pmol} / \mathrm{L}$ in two samples during treatment. One resulted in a repeat GnRH test (estradiol 320 pmol/L, peak LH/FSH 0.6/0.6 IU/L). The second girl with an increased estradiol (estradiol 380 pmol/L, basal LH 0.2 IU/L) stopped therapy shortly after at age 12.3 years. There was a trend towards a more advanced BA in girls with a detectable estradiol concentration at diagnosis compared to those with no detectable estradiol $(p=0.095)$ (Figure 5). This observation was not present at the end $(p=0.944)$ (Figure 5).

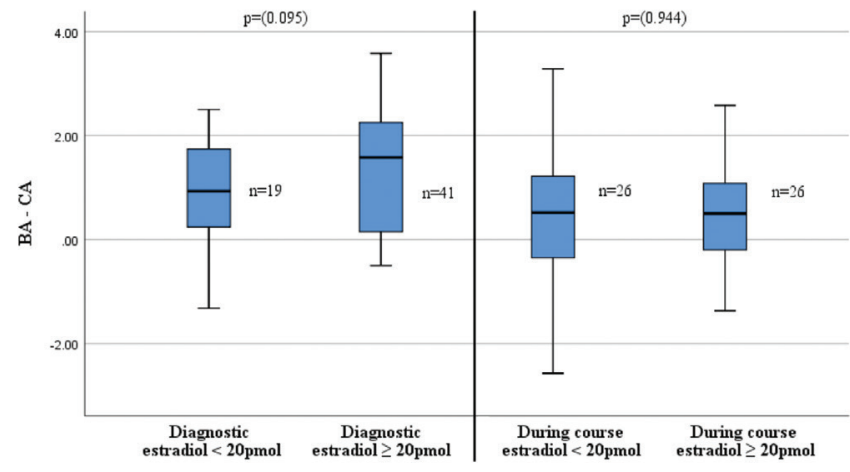

Figure 5. Bone age advancement compared with estradiol $(<20$ pmol versus $\geq 20$ pmol) at diagnosis and at the end of therapy

$B A$ : bone age, $C A$ : chronological age

The four girls who had a LH/FSH ratio $>1$ on repeat GnRH stimulation testing never had detectable estradiol concentrations during treatment. Eight girls with prepubertal $\mathrm{GnRH}$ test responses on retesting previously had detectable 
estradiol concentrations, also when discounting initial, possibly unsuppressed, concentrations sampled within the first three months of GnRHa treatment.

\section{Intensification of Treatment}

Treatment was intensified by reducing the GnRHa dosing interval to three weeks in 17 girls $(22.3 \%)$. Most often this decision was based on multifactorial variables such as increased pre-injection basal LH concentrations, stimulated LH/FSH ratios $>1$ or recordable concentrations of estradiol but in some cases also due to the impression of clinical progression with regards to breast development. The mean time from onset of treatment to the first intensification was 1.3 years (range 0.2 to 4.4 ).

Basal LH concentrations $(n=59)$ were sampled in 14 girls who had an increment in the GnRHa dosing interval to three weeks, after which point none had signs of breast development. The majority of the samples $(n=44,74.5 \%)$ in 12 girls $(85.7 \%)$ persistently had a pre-injection basal $\mathrm{LH} \geq 0.3 \mathrm{IU} / \mathrm{L}$ (median 0.4 , range 0.3 to $1.8 \mathrm{IU} / \mathrm{L}$ ). Two of three girls with a basal LH concentration $<0.3 \mathrm{IU} / \mathrm{L}$ prior to intensification developed pubertal pre-injection basal $\mathrm{LH}$ concentrations $\geq 0.3 \mathrm{IU} / \mathrm{L}$ after shortening the dosing interval.

\section{Discussion}

In this large cohort of 74 girls with $\mathrm{CPP}$, pre-injection basal LH remained at pubertal concentrations during GnRHa therapy, in spite of a lack of clinical pubertal progression (breast development), and a significant decline in BA and height SDS.

All girls were followed consecutively and $87.8 \%$ of girls had pre-injection basal $\mathrm{LH}$ concentrations $\geq 0.3 \mathrm{IU} / \mathrm{L}$ at some point in time during GnRHa therapy. Even after medical intensification, basal LH did not drop to prepubertal concentrations, but remained as high as $1.8 \mathrm{IU} / \mathrm{L}$. Thus, elevated concentrations of LH did not indicate insufficient pituitary suppression as the girls never showed signs of breast tissue development, BA advancement or had increased growth velocity. In line with this report, Wiromrat and Panamonta (9) found that in spite of pubertal basal LH concentrations during GnRHa treatment, clinical measures such as Tanner stage, BA and decreased growth velocity indicated sufficient pituitary suppression. Other smaller studies in girls treated with a $50 \mathrm{mg}$ histrelin implant have also reported elevated LH concentrations during treatment $(14,15)$.

One study in girls treated with a $50 \mathrm{mg}$ histrelin implant suggested that continuous low-concentration LH secretion tapered off over time as basal LH concentrations decreased during the course of therapy (14). We did not observe this temporal decline in LH concentrations, similar to findings in another study using leuprorelin $3.75 \mathrm{mg}$ (9). Whether the shorter half-life of leuprorelin $3.75 \mathrm{mg}$ allows breakthrough gonadotropic activity at GnRHa trough concentrations towards the next injection remains speculative. Growth velocity and pubertal progression, however, did not advance, indicating that any breakthrough at hypothalamic/pituitary level was not of clinical significance, supporting the efficacy of the leuprorelin dose.

The majority (86.2\%) of our repeat GnRH stimulation tests $(\mathrm{n}=25)$ were anteceded by pubertal LH concentrations (0.3$2.2 \mathrm{IU} / \mathrm{L})$ but on repeat stimulation none had a peak $\mathrm{LH}$ $>3.1 \mathrm{IU} / \mathrm{L}$

Consequently, basal LH concentrations had a low specificity of only $12.0 \%$, incorrectly suggesting that girls were not biochemically suppressed during GnRHa treatment when compared to the repeat GnRH stimulation tests. The same observation has been found in other studies in girls treated with histrelin implants $(14,15)$. These findings indicate that, clinicians need not be concerned about elevated LH concentrations during GnRHa therapy, in our series reaching as high as $2.4 \mathrm{IU} / \mathrm{L}$, if there are no other indicators of pubertal progression, such as breast development, BA and increased growth velocity.

Lee et al (16) found that basal LH concentrations $<0.60 \mathrm{IU} / \mathrm{L}$ and $0.75 \mathrm{IU} / \mathrm{L}$ predicted $70.0 \%$ and $60.0 \%$, respectively, of girls sufficiently suppressed during GnRHa treatment. A higher cut-off for basal LH identifies more girls with breakthrough gonadotropic activity (increased sensitivity) but with a reduced specificity (correctly suppressed girls) meaning that caution not to overlook unsuppressed girls should be warranted as the cut-off rises (16).

We, like others $(9,14,15)$, question the advantage of including routine basal LH concentrations as a monitoring strategy for pituitary suppression during GnRHa therapy. Consecutive clinical assessment assisted by growth velocity and BA is likely superior as a first line strategy. In case of doubt about progression of puberty, which may be the case during assessment of breast development in a girl with an increasing BMI, analysis of a basal LH may assist in deferring the suspicion, if not elevated. As overtreatment, which has socioeconomic costs $(4,6)$ and increase the burden of unnecessary painful injections (6), should be avoided, our results support the recommendation that GnRH stimulation testing should be considered the gold standard to evaluate suppression during GnRHa treatment (8). 
Weight gain during GnRHa treatment has already been highlighted and rise in BMI SDS was also observed in our group $(17,18)$.

A tendency towards a more pronounced advancement of BA at diagnosis was seen in girls who had a recordable estradiol concentration compared to girls with no detectable estradiol. This may likely reflect the maturing effect of estradiol on bone (19). The difference was insignificant and the question of whether this was a true trend, due to inaccuracy of paraclinical measurements or an underpowered study remains unanswered.

Eight girls with prepubertal responses on repeat GnRH stimulation testing had detectable estradiol during GnRHa treatment. Estradiol concentrations were not in accordance with pre-injection basal LH, nor clinical pubertal progression. It is widely known that low and fluctuating concentrations of estradiol around initiation of puberty make them difficult to measure $(20,21)$, and we question the reliability of estradiol measurements in girls during GnRHa treatment (22).

\section{Study Limitations}

Due to the retrospective design of our study, suspicion of clinical pubertal progression was not necessarily confirmed by a repeat $\mathrm{GnRH}$ stimulation test prior to medical intensification.

In addition, we encountered only four girls with a LH/FSH $>1$ during GnRH retesting, which did not add to the evaluation of suppression. Thus, a comparison of biochemically unsuppressed children to suppressed children was not possible, which is ultimately needed to answer the question at what concentration unstimulated basal LH may indicate reversal of pituitary suppression.

The electro-chemiluminescense immunoassay used to analyze LH concentrations had a detection limit of $0.1 \mathrm{IU} / \mathrm{L}$, and was thus not as sensitive as other assays (15). However, we aimed to assess the highest concentrations of LH, for which reason this did likely not affect out results.

Estradiol was inappropriately elevated in two cases. Although our estradiol analyses were undertaken in the same laboratory on an electro-chemiluminescense immunoassay, tandem mass-spectrometry, which is more accurate, particularly when analyzing small concentrations, was not used.

\section{Conclusion}

Basal LH concentrations often remain at pubertal concentrations during GnRHa treatment, but does not necessarily reflect insufficient gonadotropic suppression. The current study emphasized that routine clinical monitoring of girls during GnRHa therapy is preferable to routine pre-injection basal LH concentrations. In cases with dubious clinical progression, a low basal LH may defer the suspicion. A repeat GnRH stimulation test however, is to be considered if doubt persists. Finally, we suggest that estradiol concentrations should not be monitored routinely in girls treated for CPP.

\section{Ethics}

Ethics Committee Approval: The study protocol was approved by the hospital management at Aalborg University Hospital (journal no: 2019-005812-58) as required by Danish law.

Informed Consent: The study was undertaken as a quality improvement study and requires no informed patient consent according to Danish law.

Peer-review: Externally peer-reviewed.

\section{Authorship Contributions}

Concept/Design: Stefanie Schubert, Amalie H. Hvelplund, Søren Hagstroem, Tina Lund Leunbach, Data Collection or Processing: Stefanie Schubert, Amalie H. Hvelplund, Tina Lund Leunbach, Analysis or Interpretation: Stefanie Schubert, Amalie H. Hvelplund, Aase Handberg, Søren Hagstroem, Tina Lund Leunbach, Literature Search: Stefanie Schubert, Amalie H. Hvelplund, Tina Lund Leunbach, Writing: Stefanie Schubert, Amalie H. Hvelplund, Aase Handberg, Søren Hagstroem, Tina Lund Leunbach.

Financial Disclosure: The authors declared that this study received no financial support.

\section{References}

1. Teilmann G, Pedersen CB, Jensen TK, Skakkebæk NE, Juul A. Prevalence and incidence of precocious pubertal development in Denmark: an epidemiologic study based on national registries. Pediatrics 2005;116:1323-1328

2. Leka-Emiri S, Chrousos GP, Kanaka-Gantenbein C. The mystery of puberty initiation: genetics and epigenetics of idiopathic central precocious puberty (ICPP). J Endocrinol Invest 2017;40:789-802. Epub 2017 Mar 1

3. Carel JC, Léger J. Clinical practice. Precocious puberty. N Engl J Med 2008;358:2366-2377

4. Neely EK, Lee PA, Bloch CA, Larsen L, Yang D, Mattia-Goldberg C, Chwalisz K. Leuprolide acetate 1-month depot for central precocious puberty: hormonal suppression and recovery. Int J Pediatr Endocrinol 2010;2010:398639. Epub 2011 Mar 6

5. Brito VN, Latronico AC, Arnhold IJ, Mendonça BB. Update on the etiology, diagnosis and therapeutic management of sexual precocity. Arq Bras Endocrinol Metabol 2008;52:18-31. 
6. Kaplowitz PB, Backeljauw PF, Allen DB. Toward More Targeted and Cost-Effective Gonadotropin-Releasing Hormone Analog Treatment in Girls with Central Precocious Puberty. Horm Res Paediatr 2018;90:1-7. Epub 2018 Jul 26

7. Bangalore Krishna K, Fuqua JS, Rogol AD, Klein KO, Popovic J, Houk CP, Charmandari E, Lee PA, Freire AV, Ropelato MG, Yazid Jalaludin M, Mbogo J, Kanaka-Gantenbein C, Luo X, Eugster EA, Klein KO, Vogiatzi MG, Reifschneider K, Bamba V, Garcia Rudaz C, Kaplowitz P, Backeljauw P, Allen DB, Palmert MR, Harrington J, Guerra-Junior G, Stanley T, Torres Tamayo M, Miranda Lora AL, Bajpai A, Silverman LA, Miller BS, Dayal A, Horikawa R, Oberfield S, Rogol AD, Tajima T, Popovic J, Witchel SF, Rosenthal SM, Finlayson C, Hannema SE, Castilla-Peon MF, Mericq V, Medina Bravo PG. Use of Gonadotropin-Releasing Hormone Analogs in Children: Update by an International Consortium. Horm Res Paediatr 2019;91:357-372. Epub 2019 Jul 18

8. Carel JC, Eugster EA, Rogol A, Ghizzoni L, Palmert MR; ESPE-LWPES GnRH Analogs Consensus Conference Group, Antoniazzi F, Berenbaum S, Bourguignon JP, Chrousos GP, Coste J, Deal S, de Vries L, Foster C, Heger S, Holland J, Jahnukainen K, Juul A, Kaplowitz P, Lahlou N, Lee MM, Lee P, Merke DP, Neely EK, Oostdijk W, Phillip M, Rosenfield RL, Shulman D, Styne D, Tauber M, Wit JM. Consensus statement on the use of gonadotropin-releasing hormone analogs in children. Pediatrics 2009;123:752-762. Epub 2009 Mar 30.

9. Wiromrat P, Panamonta O. Elevated Random Luteinizing Hormone is an Unreliable Indicator for Pubertal Suppression in Girls Treated with Monthly Leuprolide for Idiopathic Central Precocious Puberty. J Clin Res Pediatr Endocrinol 2019;11:227-233. Epub 2018 Dec 28

10. Neely EK, Wilson DM, Lee PA, Stene M, Hintz RL. Spontaneous serum gonadotropin concentrations in the evaluation of precocious puberty. J Pediatr 1995; 127:47-52.

11. Kim HK, Kee SJ, Seo JY, Yang EM, Chae HJ, Kim CJ. Gonadotropinreleasing hormone stimulation test for precocious puberty. Korean J Lab Med 2011;31:244-249. Epub 2011 Oct 3

12. Marshall WA, Tanner JM. Variations in pattern of pubertal changes in girls. Arch Dis Child 1969;44:291-303.

13. Tinggaard J, Aksglaede L, Sørensen K, Mouritsen A, Wohlfahrt-Veje C, Hagen CP, Mieritz MG, Jørgensen N, Wolthers OD, Heuck C, Petersen JH, Main KM, Juul A. The 2014 Danish references from birth to 20 years for height, weight and body mass index. Acta Paediatr 2014;103:214224. Epub 2013 Dec 3

14. Neely EK, Silverman LA, Geffner ME, Danoff TM, Gould E, Thornton PS. Random unstimulated pediatric luteinizing hormone levels are not reliable in the assessment of pubertal suppression during histrelin implant therapy. Int J Pediatr Endocrinol 2013;2013:20.

15. Lewis KA, Eugster EA. Random luteinizing hormone often remains pubertal in children treated with the histrelin implant for central precocious puberty. J Pediatr 2013;162:562-565. Epub 2012 Oct 3

16. Lee PA, Luce M, Bacher P. Monitoring treatment of central precocious puberty using basal luteinizing hormone levels and practical considerations for dosing with a 3-month leuprolide acetate formulation. J Pediatr Endocrinol Metab 2016;29:1249-1257.

17. 17 Anık A, Çatlı G, Abacı A, Böber E. Effect of gonadotropin-releasing hormone agonist therapy on body mass index and growth in girls with idiopathic central precocious puberty. Indian J Endocrinol Metab 2015;19:267-271.

18. Kim SW, Kim YB, Lee JE, Kim NR, Lee WK, Ku JK, Kim EJ, Jung $\mathrm{SH}$, Chung $\mathrm{W}$. The influence of gonadotropin releasing hormone agonist treatment on the body weight and body mass index in girls with idiopathic precocious puberty and early puberty. Ann Pediatr Endocrinol Metab 2017;22:95-101. Epub 2017 Jun 28

19. Kunz GJ, Sherman TI, Klein KO. Luteinizing hormone (LH) and estradiol suppression and growth in girls with central precocious puberty: is more suppression better? Are pre-injection LH levels useful in monitoring treatment? J Pediatr Endocrinol Metab 2007;20:1189-1198.

20. Middle JG, Kane JW. Oestradiol assays: fitness for purpose? Ann Clin Biochem 2009;46:441-456. Epub 2009 Oct 19

21. Rosner W, Hankinson SE, Sluss PM, Vesper HW, Wierman ME. Challenges to the measurement of estradiol: an endocrine society position statement. J Clin Endocrinol Metab 2013;98:1376-1387. Epub 2013 Mar 5

22. Frederiksen H, Johannsen TH, Andersen SE, Albrethsen J, Landersoe SK, Petersen JH, Andersen AN, Vestergaard ET, Schorring ME, Linneberg A, Main KM, Andersson AM, Juul A. Sex-specific Estrogen Levels and Reference Intervals from Infancy to Late Adulthood Determined by LCMS/MS. J Clin Endocrinol Metab 2020;105:754-768. 